\title{
ECOLOGICAL CRITERIA IN THE FUNCTION OF CONSTRUCTION METHODS AND APPLICATION OF DIFFERENT MATERIALS
}

\section{Ozrislava Milinkovic}

Faculty of Applied Management Economics and Finance, Belgrade, Serbia

\section{Snezana Trmcic}

Faculty of Applied Management Economics and Finance, Belgrade, Serbia

OMESTE

JEL Category: Q57

\begin{abstract}
The European Construction Industry (ECI) is facing the challenge of increased consumption of energy, resources, environmental threats and climate changes which are dictating the necessity of using technology that can help in rationalizing consumption of resources. Additionally, environmental protection became a top priority for ensuring sustainable development, maintaining very high international environmental standards, and revitalizing important role of $\mathrm{ECl}$ in the world economy. To evaluate the impact of construction objects on the environment, it is necessary to consider all phases of construction, including the use of natural raw materials needed for the manufacturing of construction materials, construction, the exploitation of objects and eventually demolition and recycling. The construction is considered as an activity that consumes the greatest amount of natural resources, such as water, wood and a variety of raw materials for the production of construction materials. The construction industry is one of the biggest air pollutants and causes high energy consumption in all phases of construction. With recycling and reuse of construction material need for natural resources can be significantly reduced. Applying multi-criteria decision-making methods enable us to objectively evaluate impact of the construction object on the environment as well as his ability to meet assigned criteria. The article is devoted to analyzing five most commonly built sports halls made with different materials and systems of construction in order to determine which one is meeting environmental criteria to the fullest extent.
\end{abstract}

Keywords: Ecological criteria, sustainable development, different materials, construction methods, environmental protection.

Address of the corresponding author:

Ozrislava Milinkovic

拝=0 ozradjurovic@yahoo.com 


\section{INTRODUCTION}

According to the Statistical Office of the Republic of Serbia, on the territory of Serbia there are 1533 primary schools, of which $50 \%$ have no sport halls for physical education and $25 \%$ have inadequate (Republicki Zavod za Statistiku, 2013). The challenge that government at all levels are facing is not only the construction of sports facilities, but also integration into European environmental standards that are recommending reduced consumption of resources and energy in all phases of construction, reduced emissions of $\mathrm{CO}_{2}$, durability and so on.

In this article we analyze the indoor sports facilities. In most cases sports halls are public facilities owned by the local governments. They are built to be used by citizens throughout the Republic. It is therefore essential that persons who are in a position to make decisions on behalf of the wider population make decisions as a result of elaborate analysis and use of multi criteria decision making methods in order to choose the sport facility that will meet European environmental standards to the fullest extent and preserve ecological balance. Thus, the vision of sustainable development has to be followed. It implies meeting the needs of present generations without compromising the ability of future generations to meet their own needs. Sustainable development makes compromise between current and long-term objectives, local and global action on environmental issues as inseparable components of human progress.

\subsection{Methodology}

Use of relevant literature, factual information and application of "Promethee" multi-criteria decision making method. Paper presents an objective selection of different materials and construction systems in the practical example of choosing best among several commonly built sports halls in terms of environmental criteria, with respect to environmental standards, and sustainable development.

\section{RESULTS OF THE RESEARCHE AND DISCUSION}

In order to select sport facility that best meets the environmental criteria, analysis was conducted on the five most commonly built sports hall made with different materials and systems of construction: "balloon hall" with wooden structure, steel hall made with "sandwich panels", hall made of clay blocks with steel roof, prefabricated hall made from reinforced concrete "sandwich" elements ( $A B$ hall) and prefabricated hall made from ferrocement "sandwich" elements (FC hall). As the most important criteria from the ecological and environmental perspective following have been taken in to the account: the degree of environmental degradation during exploitation of raw material from the nature, the extent of environmental pollution during the production and processing of construction materials, harmful substances and radiation from the material, the durability of construction materials and possibility of recycling, energy needed for production of building material and energy consumption during exploitation of facility.

\section{1 "Ballon hall" with wooden structure}

The supporting structure is arched and large in span usually made from laminated wood because it's impossible to find natural timber of such dimensions and shape. Laminated wood is easily produced in static modal size, and dimensions. PVC materials (polyvinyl chloride) are the cheapest and most commonly used materials for covering the balloon hall.

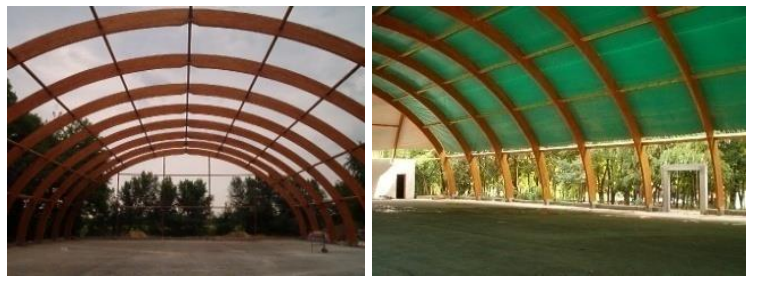

Fig. 1 Ballon hall with wooden structure

Properties that make this fabric attractive for use in construction are their low mass and transparency. The downside of these types of sport facilities is that they react quickly to the temperature changes in the external environment 
which significantly affects end user comfort and more power is needed for their cooling or heating. They also have very short lifespan.

\subsection{Steel hall made with "sandwich" panels}

Each steel hall consists of primary and secondary structures. The primary structure consists of the supporting frame and the stabilizing elements which have a role to ensure the stability of buildings and to transmit the load to the reinforced concrete foundation. The secondary structure consists of roof and facade substructure. The steel structure is filled with water proofed steel panels which consists of two shallow profiled galvanized $\left(275 \mathrm{~g} / \mathrm{m}^{2}\right)$ and painted steel sheets (0.5 $-0.7 \mathrm{~mm}$ thick) with broad, non-flammable insulating core of laminated mineral wool $\left(50-240 \mathrm{~mm}\right.$ thick, specific gravity of $\left.120 \mathrm{~kg} / \mathrm{m}^{3}\right)$. All three layers are connected in a compact sandwich element that provides the necessary capacity, tightness and compactness. The core made from non-combustible laminated wool provides thermal and acoustic insulation and high fire resistance of the sandwich elements (Trimo, 2010).

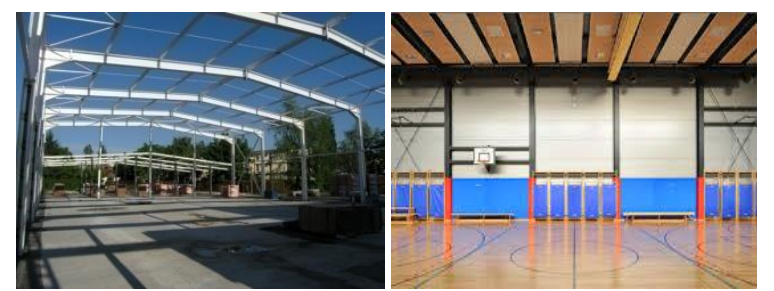

Fig. 2 Steel hall made with "sandwich" panels

\subsection{Hall made of clay blocks with steel roof}

This type of hall is built using system of strip foundation and load-bearing walls made of clay blocs with steel roof. Clay blocks are standard type of clay blocks with horizontal and vertical holes that allow the safe and economical production of the supporting and separating walls. They represent environmentally friendly product with high durability and quality. The walls made of hollow clay blocks provide good vapor permeability, sound and thermal insulation. Clay block can be insulated with polystyrene or mineral wool. For the purposes of this study we will presume that the clay blocks are insulated with 10 $\mathrm{cm}$ thick mineral wool.
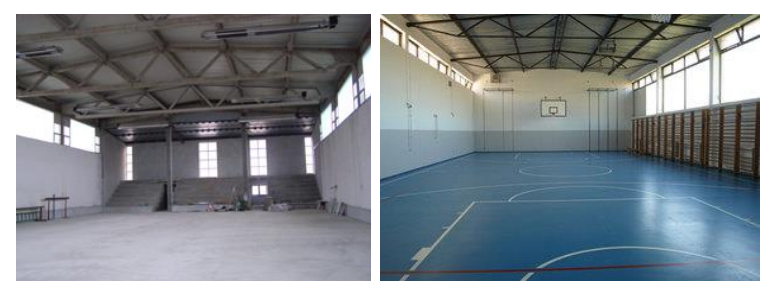

Fig. 3 Hall made of clay blocks with steel roof

\subsection{Prefabricated hall made from reinforced concrete "sandwich" elements ( $A B$ hall)}

Halls built from reinforced concrete prefabricated sandwich elements consist of two concrete layers which are mutually separated by a layer of insulation. These elements can be used as bearing walls, beams or internal walls .Interest for these types of sandwich panels is on the rise for the past two years because they represent costeffective, attractive and energy-efficient walls that can be used for the halls as well as for the residential buildings (Keenehan, Concannon, \& Hajializadeh, 2012). Energy efficiency of these elements depends on the connectors used to connect elements as well as the insulation. Although there are several kinds and types of insulation on the market, concrete sandwich panels use hard insulation because their properties are the most compatible with concrete in terms of moisture absorption, stability, size and flexibility (Seeber, 1997).

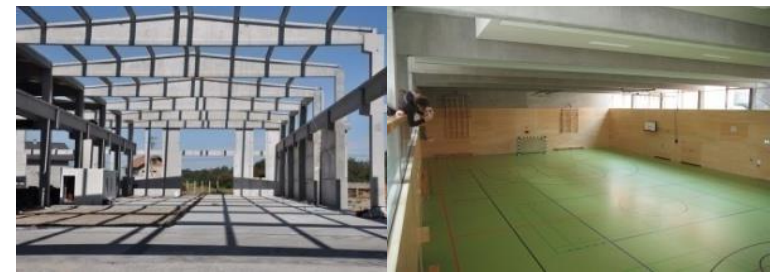

Fig. 4 Prefabricated hall made from reinforced concrete "sandwich" elements

\subsection{Prefabricated hall made from ferrocement elements (FC hall) \\ "sandwich"}

Ferrocement is a type of fine-grained thinreinforced concrete reinforced with wire lath and single layer of wire mesh. There are five methods used to produce ferrocement structures from 
which the simplest and most efficient in practice has proved to be "MC" building system that will be described in more detail below.

Halls built using "MC" system of construction are prefabricated. It consist of ferrocement, prefabricated, thermo insulated, "sandwich " type elements. These elements have a thickness of 19 $\mathrm{cm}$ in cross-section. The base is made of ferrocement while the thermal insulation layer is made from simprolit (Styrofoam balls dipped in cement milk). Thermo insulated layer is $15 \mathrm{~cm}$ thick and also serves as a protection against fire.

Elements made in such a way are transported to the construction site, assembled over auxiliary steel structures and directly connected with polygonal reinforced concrete arch which is formed on the spot. Halls constructed in such a way are completely resistant to fire, earthquakes, and all the storms, including hurricanes (MC system, 2014).

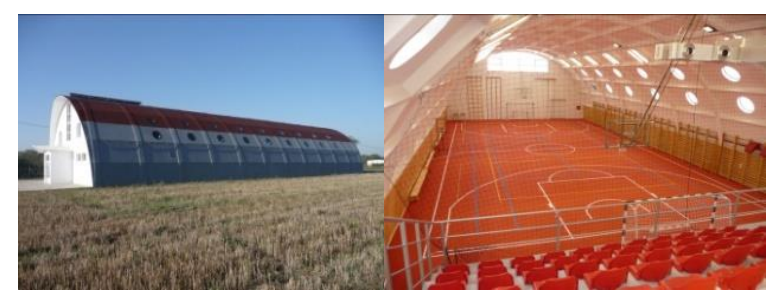

Fig.5 Prefabricated hall made from ferrocement sandwich elements

\section{CRITERIA USED FOR ANALYZING CONSTRUCTION MATERIALS FROM PERSPECTIVE}

Criteria used to analyze sport hall from environmental perspective are :

- The degree of environmental degradation in the process of extracting raw materials from the nature.

- The degree of environmental pollution during production and processing of construction materials.

- Harmful substances and radiation from materials.

- Durability and possibility of recycling construction materials.

- Energy needed for production of construction materials.
- Energy needed for exploitation of sport facilities.

\subsection{The degree of environmental degradatio in the process of extracting raw materials from the nature}

Pedosphere is the outer layer of the earth which consists of the land. Land is a source of energy, minerals, place where food is produced and where most of the living organisms including human beings are living. The amount of land available to man is limited and represents a nonrenewable resource. Growth of population leads to deforestation, reduction of land covered with plants and increase of land used for construction of roads buildings and other infrastructural objects. All of it inevitably leads to chemical and physical pollution of pedosphere which as a consequence has pollution of underground waters, rivers, lakes, plants air pollution and climate changes. Constant pollution of air, land and underground waters has a long lasting impact on the environment endangering human health and disturbing ecological balance (Poljoprivredni institut Republike Srpske, 2009).

\subsection{The degree of environmental pollution during production and processing of construction materials.}

During the production and processing of construction materials, the environment is polluted in different ways and one of the most alarming is through the emission of greenhouse gases especially carbon dioxide $\left(\mathrm{CO}_{2}\right)$. According to Loncaric B. (2012) polluted air is one that has received the gas, steam, smoke, dust and other materials from a variety of sources in amounts which may harm the health of people, environment and material assets. Clean air is composed of: nitrogen $\left(\mathrm{N}_{2}\right) 78.09 \%$, oxygen $\left(\mathrm{O}_{2}\right)$ $20.94 \%$, carbon dioxide $\left(\mathrm{CO}_{2}\right) \quad 0.03 \%$, and the remaining $0.94 \%$ consists of other dry inert gases such as helium, argon, krypton, xenon, and so on. The biggest air polluter is industry among them construction industry, metal and non metal and chemical industry take significantly high place. Consequences of air pollution are: acidic rain and 
degradation of land, "greenhouse gasses" effect and variety of health problems in humans.

\subsection{Harmful substances and radiation from materials}

Harmful substances and radiation from the material during the production, exploitation and destruction of construction products adversely affect the health of people and the entire planet. State agencies continue to study many chemical additives used to build and improve the performance of construction materials. Many are rated as extremely toxic, even carcinogenic. In Serbia, the prohibition or restriction the use of certain building materials and chemicals is done according to the rules of Serbian Chemical Agency. Among three most dangerous chemicals used in Serbia are: radon, polyvinyl chloride and formaldehyde.

PVC stands for polyvinyl chloride or thermoplastic polymer. Over $50 \%$ of this material is used in the construction industry as a hard plastic to make window profiles or plates and as a soft plastics roof and wall insulation materials and so on. PVC increasingly replaces traditional building materials mainly due to much lower prices. PVC material is a very harmful to people's health because of the high proportion of chlorine which is used for its production. During production, use and disposal of material highly toxic and carcinogenic gas dioxin is released. Exposure to vapors of dioxin causes serious health consequences (National Library of Medicine, 2013).

Formaldehyde is a colorless strong smelling chemical used in the construction industry in some insulation materials and construction adhesives. All materials that contain formaldehyde are releasing gas or emitting toxic fumes that causes serious respiratory problems and on the long run causes cancer. All laminated wood are containing formaldehyde (American Cancer Society, 2103).

Radon is an inert radioactive gas, which can be found on the surface of the entire planet Earth, comes from the decaying of radium, and it's also generated by uranium contained in the earth's crust. Radon can be segregated from deeper layers of soil and underground water but it can also be extracted from building materials that contains slag ash or red brick (United States Environmental Protection Agency, 2014).

\subsection{Durability and possibility of recycling construction materials}

Each material has its own life expectancy, or the period during which it will keep its properties in the same or approximate form observing from the time it's started being used. After the loss of their properties as some materials can be used in its primary purpose some can be recycled and reused or used as raw material in further processing and some has to be disposed on the landfill. The durability of the material largely defines the lifetime of the facility and affects the energy balance of the building for a specific reference period.

\subsection{Energy needed for production of construction materials}

Construction materials are generally produced by processing natural raw materials. In order to produce a certain construction material, it is necessary to spend a certain amount of energy to be able to transform the natural raw material in to usable building materials. Except for emission of harmful gasses production process often requires a great amount of energy spent. With recycling, and getting materials from recyclables the amount of energy used can be reduced. In the further chapters the amount of energy needed for most commonly used building materials will be calculated.

\subsection{Energy needed for exploitation of sport facilities}

Most of the energy needs for heating of object due to the large surfaces and ranges that are preventing implementation of adequate insulation are by far exceeding all others. Energy consumption has a large impact on the ecology, because of the emission of harmful substances needed for the production of energy itself. This criterion should be given considerable attention since its cumulative effect over the years has a significant impact on the balance. 


\section{MULTIPLE CRITERIA DECISION MAKING METHOD - "PROMETHEE"}

The problem of selecting the best among several types of the sports hall according to the environmental criteria falls into bad structured problems. The problem will be analyzed using the "Visual Promethee" method. Characteristics of the "Promethee" methods are:

- In the first step of problem solving, criteria that are characterizing the problem, and are relevant to decision maker, should be welldefined.

- Alternative solutions to problem should be developed. They represent alternative versions of characteristics of buildings that need to be compared and ranked. To each criteria weight ratio is added that reflects his importance from the perspective of decision-maker (Nikolic \& Borovic, 2009).

- According to the criteria defined for each action appropriate values in absolute terms are entered. They can also be in unparalleled units.

- Elaborating the results for multi criteria analysis with verbal and graphic interpretation of the obtained ranges using "Gaia" method.

When evaluating investment projects criteria for evaluation are usually classified into four groups: economic, technical and technological, sociopolitical and environmental criteria. In this analysis, the focus is on the environmental criteria. For numeric processing of the problem using "Promethee" and "Gaia" methods multi criteria decision making, software "Decision Lab 2000 " has been used. This is a commercial name for a software product distributed by "Visual Decision" from Canada (Promethee Gaia-net, 2014).

\subsection{Analyzing the problem of} selecting best among several types of sports hall using "Promethee" method from environmental perspective

In solving the problem of selecting the best type of sports halls according to the environmental perspective: the degree of environmental degradation in the process of extracting raw materials from the nature should be as small as possible, emission of harmful substances and radiation from the material as small as possible, durability of building materials and the possibility of recycling as high as possible, energy used for production of building materials as small as possible, energy consumption needed for the exploitation of the object as small as possible.

For the reasons of the different distances of pillars for different objects $(4-8 \mathrm{~m})$, all analyzes have been based on the halls that are $48 \mathrm{~m}$ long. This way, we will again compare objects of the same size and volume. All analyzes are comparable and there is no reference value.

\subsection{Values used to used to analyze the degree of environmental degradation in the process of extracting raw materials from the nature}

Exploitation of raw materials from the nature results in long turn impact on the environment. This criterion refers to the creation of quarries, degradation of agricultural land, excavation sites and deforestation. The criterion is impossible to describe numerically therefore narrative criteria will be used.

\subsection{1 "Balloon" hall with wooden structure;}

Basic raw materials which are taken from nature are natural salt, oil and wood. Exploitation of natural salt has no lasting harmful effects on the nature while exploitation of oil leads to the formation of greenhouse gases over the crude oil which is extracted from the soil. These gases are then dissipated into the air and they are increasing the level of carbon dioxide which has a lasting impact on the environment (Grec \& Maior, 2008). PVC materials which are used to cover balloon hall are obtained from the oil just like synthetic polymers. The composition of wood adhesives is slightly varying from one brand to another but they are all based on PVA (polyvinyl aldehyde) and they contain synthetic polymers which are enhancing their ability of bonding. Timber is obtained by deforestation and over the years leads to erosion and climate change. Taking into account the above factors to this criterion, we assign descriptive value "bad". 


\subsubsection{Steel hall with "sandwich panels;}

The basic material for insulation of the sandwich panels is mineral wool. Mineral wool is produced from the mineral such as diabase, basalt, dolomite, and others. These minerals are available in strip mine. Steel sheets are made from iron which previously has been cleaned from impurities such as sulfur, phosphorus, and silicon. Excavation of minerals and iron from the earth's crust influence the environment before during and after excavation. Consequences vary (depending on the type of ore and the extent of excavation) from erosion sedimentation, pollution of the nature around the excavation site etc. Also it is important to note that the panels are coated with PVC protective layer that is derived from oil which has already been discussed in the previous paragraph. Taking into account the above factors to this criterion, we assign descriptive value "medium".

\subsubsection{Hall made of clay blocks with steel roof;}

The basic material from production of this type of hall is clay. Clay is the type of soil which in nature appears as a consequence of rocks decomposition and its extraction. Depending on the volume of excavation can cause erosion, damage to the natural habitat of animals, degradation of rivers, etc. It should be noted that the excavation and extraction of clay releases the radioactive gas radon, which is very harmful to human health .Insulation of these halls is made from mineral wool or polystyrene. Raw materials for mineral wool have already been described. Polystyrene is product of oil. Taking into the account above factors, to this criterion, we assign descriptive value "bad".

\subsubsection{Prefabricated AB hall;}

The base material is cement which is obtained by grinding a material called clinker. Clinker is produced by extraction and processing limestone, clay, bauxite, quartz sand etc.. In the production of this type of hall next to the cement, materials such as steel and polystyrene have been used. Polystyrene is made from synthetic polymers styrene, which is a by-product of oil. Polystyrene can be easily recycled with minimum energy consumption, as opposed to the mineral wool.
Taking into account the above factors to this criterion, we assign descriptive value "medium".

\subsubsection{Prefabricated FC hall;}

Materials used for the production of this hall are: steel, cement and polystyrene. About the origin of these materials and their impact on the environment it has been discussed in the previous paragraphs. Taking into account the above factors to this criterion, we assign descriptive value "medium".

\subsection{Values used to analyze degree of environmental pollution during production and processing of construction materials}

This criterion will be calculated based on the values given in table 2 .

Table 1. Production of carbon dioxide for standard and alternative construction materials

\begin{tabular}{|l|r|}
\hline Type of material & $\begin{array}{c}\mathbf{C O}_{2} \text { emission } \\
\text { (kg/t) }\end{array}$ \\
\hline Limestone & 12 \\
\hline Portland Cement & 170 \\
\hline Unreinforced concrete MB15-20 & 370 \\
\hline Reinforced concrete MB 30 & 132 \\
\hline Soft wood processed & 570 \\
\hline $\begin{array}{l}\text { Glue laminated wood(PVA } \\
\left.\text { adhesive 120 kg/m }{ }^{3}\right)\end{array}$ & 279 \\
\hline Portland cement (64-73\% slag) & 850 \\
\hline Clay & 430 \\
\hline Tile & 1,720 \\
\hline Steel bars and plates & 3,900 \\
\hline Polypropylene injection & 500 \\
\hline Mineral wool & 2,700 \\
\hline Polystyrene & 2,410 \\
\hline PVC & \\
\hline
\end{tabular}


Table 2. Total emission of $\mathrm{CO}_{2}$ needed for production of sport halls

\begin{tabular}{|l|r|}
\hline Type of sport hall & $\begin{array}{c}\text { Total emission of } \\
\mathrm{CO}_{2}(\mathrm{t}) \text { needed for } \\
\text { production of } \\
\text { materials }\end{array}$ \\
\hline $\begin{array}{l}\text { "Balloon" hall with } \\
\text { wooden structure }\end{array}$ & 34.93 \\
\hline $\begin{array}{l}\text { Steel hall with } \\
\text { "sandwich" panels }\end{array}$ & 88.45 \\
\hline $\begin{array}{l}\text { Hall made of clay } \\
\text { blocks with steel roof }\end{array}$ & 95.47 \\
\hline Prefabricated AB hall & 116.88 \\
\hline Prefabricated FC hall & 87.28 \\
\hline
\end{tabular}

\subsection{Values used to analyze harmful substances and radiation from materials}

- Balloon" hall with wooden structure;

Cooling, heating and deterioration of PVC materials used to cover balloon hall leads to the release of toxic gas - dioxin which cause cancer and respiratory problems. Laminated wood used in balloon halls and cover in industrial adhesive contains formaldehyde which evaporates and causes the cancer and respiratory problems. According to the criterion harmful substances and radiation from the material, this hall is rated as "poor".

- Steel hall with "sandwich" panels;

In addition to steel, which is not harmful to human health, this type of hall consists of sandwich panels insulated with mineral wool which doesn't come in contact with the end user therefore in this case it be considered safe for human health. Sandwich panels are coated with PVC film to ensure water resistance. PVC in lesser extent emits toxic fumes discussed in the previous paragraph. According to the criterion of harmful substances and radiation from material, this hall is rated as "medium".

- Hall made of clay blocks with steel roof; Hall is made from materials that are not hazardous to human health but red clay can release toxic gas radon which causes various respiratory problems. According to the criterion of harmful substances and radiation from material, this hall is rated as "medium".
- Prefabricated AB hall;

Next to the cement and mineral wool insulation that doesn't come in contact with the end user all the other materials in this type of hall are not harmful to human health. According to the criterion of harmful substances and radiation from material, this hall is rated as "good".

- Prefabricated FC hall;

Next to the cement and polystyrene that doesn't come in contact with end user all the other materials are not hazardous to human health. According to the criterion of harmful substances and radiation from material, this hall was assessed as "good".

\subsection{Values used to analyze durability and possibility of recycling}

This criterion will also be described according to durability and possibilities of recycling the materials (re-use in the same or other processes).

- "Balloon" hall with wooden structure;

PVC textile foils are mainly used until the end of their life cycle, which amounts to 20 years; therefore in their original form they cannot be reused. In Serbia center for recycling PVC materials doesn't exist, instead they are disposed to landfill. Life cycle of laminated wood is $30-50$ years if maintained properly, therefore the life cycle of entire hall is measured by it. Laminated wood can be recycled and used for the production of medium density fiberboards (MDF). According to the durability and possibility of recycling "balloon" hall is ranked "bad".

- Steel hall with "sandwich" panels;

When it's not in direct contact with aggressive atmospheric conditions, and when it's located in closed space with adequate protection against corrosion steel has a long lifespan, sometimes for more than 100 years. Steel is easily recycled and when it's recycled saves up to $70 \%$ compared to the production of primary raw materials. Sandwich panels are not suitable for recycling mostly because they are made of thin metal sheets reinforced with thick layer of mineral wool. Thin metal sheets are recyclable but it's very difficult to separate them from mineral wool insulation layer or anticorrosion coating. Mineral wool is not recyclable. The lifespan of sandwich 
panels is according to the manufacturer's declaration. If manufacturer is high quality life spam is usually about 30 years. The lifespan of mineral wool is according to the manufacturer's declaration usually around $20-40$ years. Due to the large percentage of steel in the total weight of object rating of durability and recycling possibility is "medium".

- Hall made of clay blocks with steel roof;

It also contains a high percentage of steel in the roof structure as well as in the reinforcement of concrete. Reinforced concrete which has been protected from the penetration of sulfates and therefore internal corrosion has a very long lifespan. Facade and mineral wool cannot be recycled. Durability of plastered façade, depending on the quality can be to 50 years. Reinforced concrete and hollow clay blocks can be used after a simple process of grinding (milling) as a basis for local roads or foundations to other construction objects. Durability and recycling possibility is rated "good".

- Prefabricated AB hall;

As the name says, the basic material used is reinforced concrete. Durability of these construction halls is very large, more than 100 years. All the reinforcement is possible to recycle as well as concrete. An insulating layer which is made from polystyrene cannot be used in their original form, but it is also entirely recycled and used as a raw material in the production of polypropylene and polystyrene containers. Almost all materials that are incorporated into $A B$ prefabricated hall are recyclable. Therefore the hall is rated "very good" according to the criterion of durability and possibility of recycling.

- Prefabricated FC hall;

The entire hall is based on reinforced concrete and insulation made from polystyrene. Plastered façade does not exist so the durability of the object is as long as durability of reinforced concrete which is more that 100 years. All the materials used in this hall are recyclable, but due to the unique method of concrete reinforcement process of recycling has to be done in several phases. Due to the more complicated process of recycling this hall is rated as "good".

\subsection{Values used to analyze energy needed for production of construction materials}

This criterion will be calculated based on values given in table 3 .

Table 3. Energy needed for production of construction materials

\begin{tabular}{|c|c|c|}
\hline Type of material & $\begin{array}{l}\text { Energy } \\
\text { needed for } \\
\text { production } \\
\text { kWh/t }\end{array}$ & $\mathrm{kWh} / \mathrm{m}^{3}$ \\
\hline Limestone & 1,200 & 1,600 \\
\hline Cement & 1,400 & 1,900 \\
\hline Aluminum & 15,300 & 40,650 \\
\hline Wood & 190 & 100 \\
\hline $\begin{array}{l}\text { Laminated wood (PVA } \\
\left.\text { adhesive } 120 \mathrm{~kg} / \mathrm{m}^{3}\right)\end{array}$ & 2,300 & 1,560 \\
\hline Steel & 2,200 & 35,500 \\
\hline Steel profiles & 4,100 & 82,000 \\
\hline Copper & 8,000 & 71,000 \\
\hline Sand & 9 & 15 \\
\hline Glass & 5,700 & 1,500 \\
\hline Clay blocks & 832 & 574 \\
\hline Ceramics & 6,200 & 14,900 \\
\hline Adobe & 1,200 & 2,200 \\
\hline Mineral wool & 6,000 & 720 \\
\hline Polystyrene & 24,600 & 490 \\
\hline Plastic & 11,000 & 11,000 \\
\hline PVC material & 21,440 & 6,400 \\
\hline
\end{tabular}

\subsection{Values used to analyze energy needed for exploitation of sports halls}

Since we assume that the analyzed objects will be heated with the same or similar power source that has the same degree of efficiency, the $\mathrm{CO}_{2}$ emissions ratio for the energy used for heating, is the same as the ratio of heat loss which are creating that need.

\subsection{Numerical interpretation of the problem ranking of the action}

Analyzing the problem of selecting the best among several types of the sports hall from the 
environmental perspective, for three criteria numerical values have been defined with appropriate physical unit. As $\mathrm{CO}_{2}$ emitted during the production of material from which sport hall have been made has an immediate effect on the environment this criterion will be allocated weight ratio 2. Emission of $\mathrm{CO}_{2}$ has twice bigger impact on the environment then other criteria; therefore all the other criteria will be allocated weight ratio 1. Criteria which cannot be measured with numerical values were measured on the descriptive scale from 1 to 5 .

Table 4. Total energy needed for production of sport halls

\begin{tabular}{|l|c|}
\hline Type of sport hall & $\begin{array}{l}\text { Total energy needed } \\
\text { for production of } \\
\text { materials }\end{array}$ \\
\hline $\begin{array}{l}\text { "Balloon" hall with } \\
\text { wooden structure }\end{array}$ & 215.13 \\
\hline $\begin{array}{l}\text { Steel hall with } \\
\text { "sandwich" panels }\end{array}$ & 286.85 \\
\hline $\begin{array}{l}\text { Hall made of clay } \\
\text { blocks with steel roof }\end{array}$ & 371.85 \\
\hline Prefabricated AB hall & 360.30 \\
\hline Prefabricated FC hall & 277.63 \\
\hline
\end{tabular}

\subsection{Analysis of obtained results}

For each criterion desirable value has been defined, or in other words if decision-maker prefers higher or lower value for the analyzed criterion. All criteria which appear has direct environmental impacts, were analyzed linearly.

\begin{tabular}{|c|c|c|c|c|c|c|}
\hline Environmental & Extracting ra... & CO2 emissio... & Harmful subs... & Durability an... & Energy need... & Exploitation... \\
\hline Unit & impact & $\mathrm{t}$ & 5-point & 5-point & kwh & kwh \\
\hline Cluster/Group & $\Delta$ & $\bullet$ & 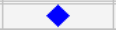 & $\Delta$ & $\Delta$ & 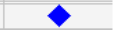 \\
\hline \multicolumn{7}{|l|}{ Preferences } \\
\hline Min/Max & $\max$ & $\min$ & $\max$ & $\max$ & $\min$ & $\min$ \\
\hline Weight & 1,00 & 2,00 & 1,00 & 1,00 & 1,00 & 1,00 \\
\hline Preference $\mathrm{Fn}$. & Linear & Usual & v-shape & Usual & Linear & Usual \\
\hline Thresholds & absolute & absolute & absolute & absolute & absolute & absolute \\
\hline - Q: Indifference & 1 & nia & nia & nia & 1,0 & n/a \\
\hline - P: Preference & 2 & nia & 2 & n/a & 2,0 & n/a \\
\hline - 5: Gaussian & nia & n/a & n/a & nia & n/a & nia \\
\hline \multicolumn{7}{|l|}{ Statistics } \\
\hline Minimum & 2 & 34,9 & 2 & 2 & 215,1 & 6,02 \\
\hline Maximum & 3 & 116,9 & 4 & 5 & 371,9 & 33,24 \\
\hline Average & 3 & 84,6 & 3 & 4 & 302,4 & 13,11 \\
\hline Standard Dev. & 0 & 27,0 & 1 & 1 & 57,7 & 10,13 \\
\hline \multicolumn{7}{|l|}{ Evaluations } \\
\hline Balloon hall $\square$ & low & 34,9 & bad & bad & 215,1 & 33,24 \\
\hline Steel hall $\square$ & moderate & 88,5 & average & average & 286,9 & 9,45 \\
\hline Hall made of clay... $\square$ & low & 95,5 & average & good & 371,9 & 8,86 \\
\hline AB prefabricated... $\square$ & moderate & 116,9 & good & very good & 360,3 & 7,97 \\
\hline EC prefabricated... $\square$ & moderate & 87,3 & good & good & 277,6 & 6,02 \\
\hline
\end{tabular}

Fig.6 "Promethee" software basic window

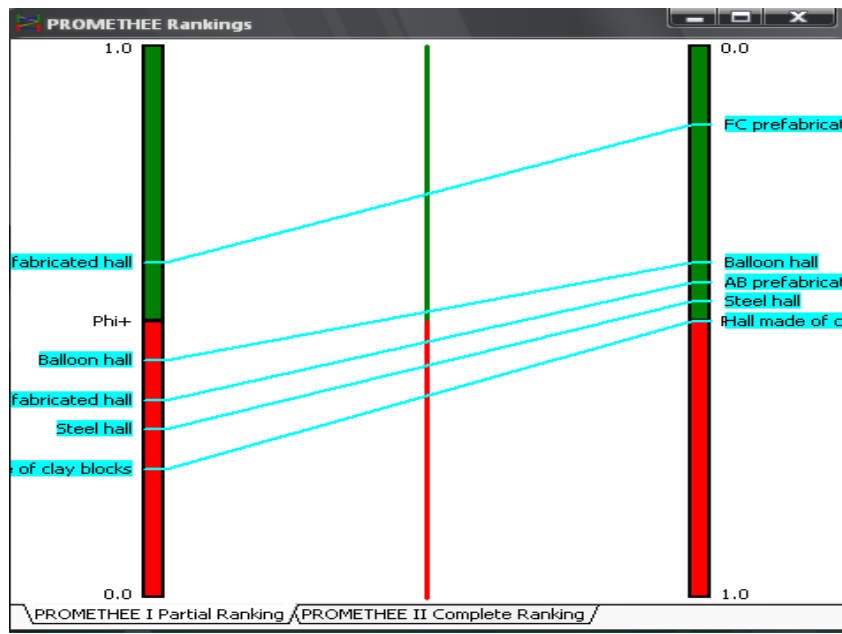

Fig. 7 "Promethee"software rankings

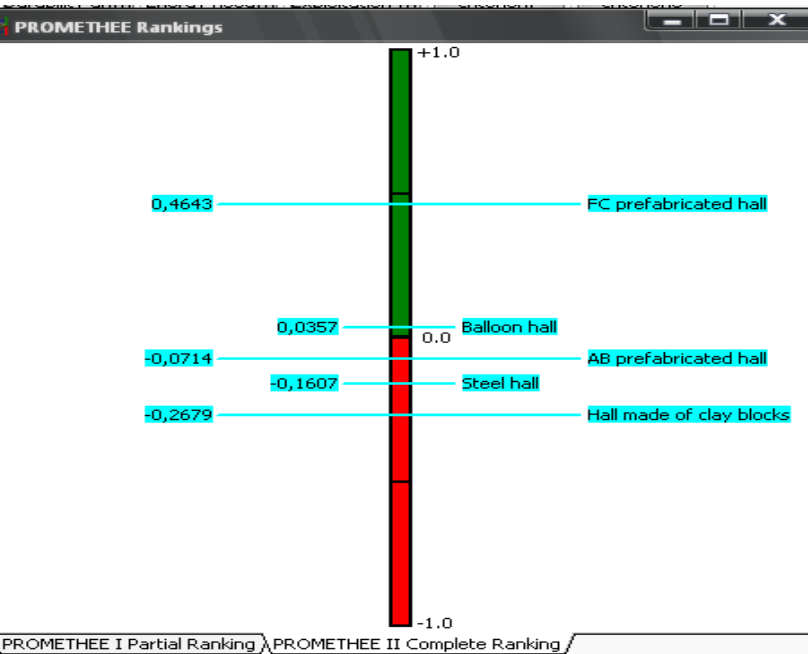

Fig. 8 "Promethee" software rankings

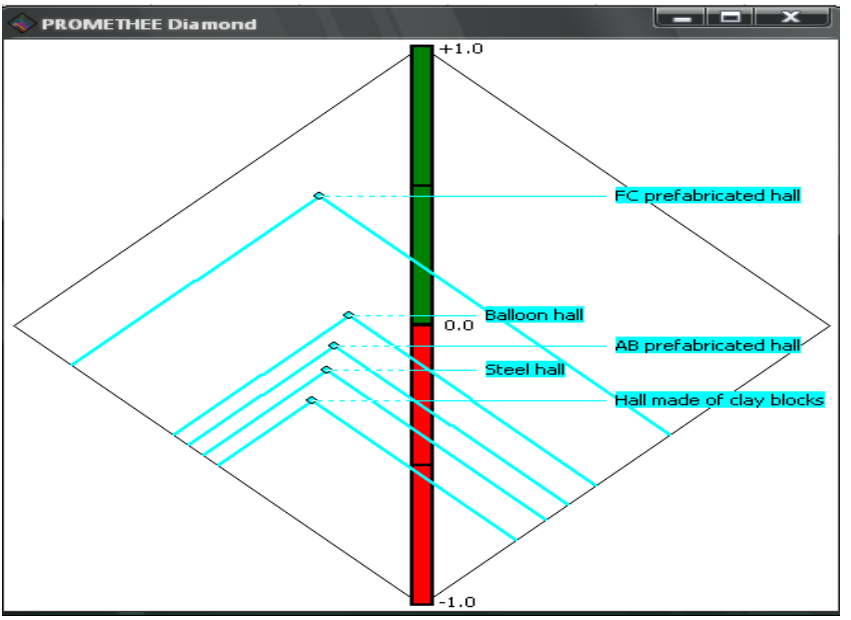

Fig 9. "Promethee" software-Diamond 


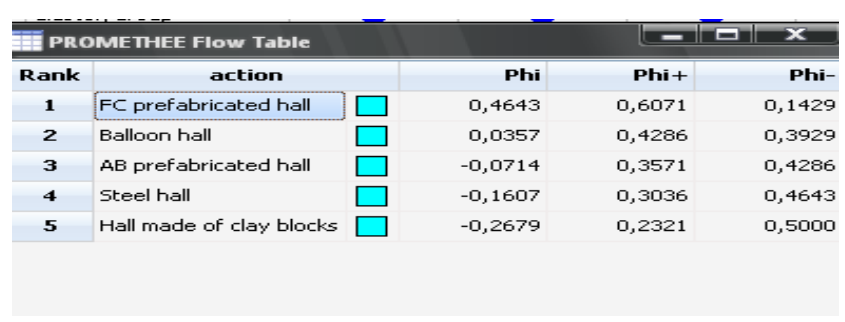

Fig. 10 "Promethee" software - Table

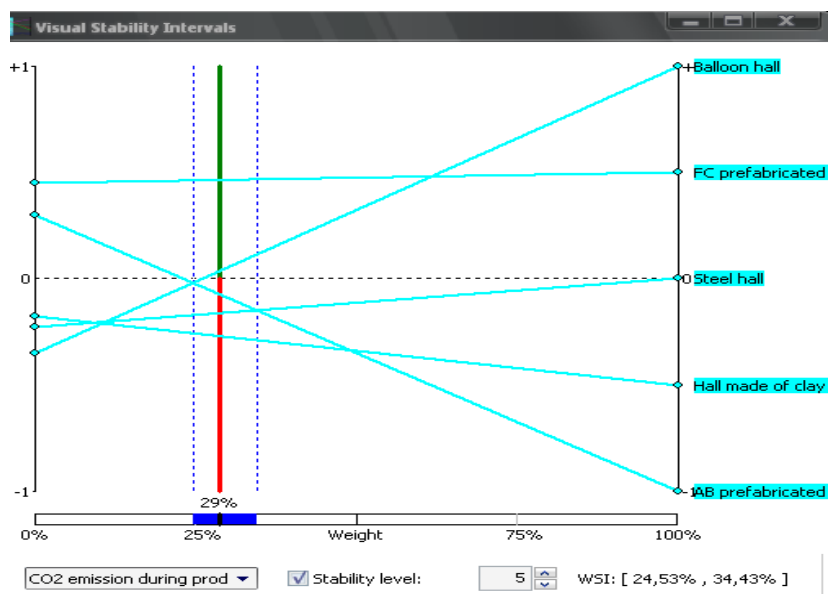

Fig.11. "Promethee" software - Stability interwals

From the graphic 7 to 11 descriptions and analysis of the problem we can see that all the solutions are comparable and the subsidiary. Area occupied by the highest-ranked sport hall covers the surface of all the others. We can see that the solutions are comparable and the subsidiary. Based on the given criteria best ranked is FC halls while the second ranked is balloon hall. Best ranked solution is stable and linear in the requested domain.

\section{CONCLUSIONS}

Using the "Visual Promethee" method following sport halls have been analyzed: "balloon" hall with wooden frame, steel hall with sandwich panels, hall made of clay blocks with steel roof, prefabricated hall of reinforced concrete elements and prefabricated hall of ferrocement sandwich elements. The analysis is carried out according to the environmental criteria. Data used in the analysis are realistic and calculated on the materials used in real life. According to the environmental perspective the best sport hall to build is prefabricated hall made of ferrocement sandwich elements. Applying the multi- criteria decision making model made it possible to evaluate different materials, systems of constructions on the practical example of choosing best among several commonly built sports halls from the environmental perspective following vision of sustainable development and environmental protection.

\section{WORKS CITEDS}

Grec, A., \& Maior, C. (2008, December). Earth oil extraction - major environmental pollution source. Environmental Engineering and Management Journal, 7(6). Preuzeto sa http://omicron.ch.tuiasi.ro/EEMJ/pdfs/vol7/no6/24_Aurica\%20Grec.pdf

Keenehan, J., Concannon, K., \& Hajializadeh, D. (2012). Numerical Assessment of The Thermal Performance of Structural Precast Panels. University College Dublin

Loncarić, B. (2012). Zagadjenje vazduha. Retrieved from: http://www.meteoplaneta.rs/wpcontent/uploads/2012/04/zagadjenja-vazduha-kao-posledice-vanrednih-dogadjanja.pdf

MC system. (2014). MC system of construction benefits. Retrieved from: http://www.milinkovicco.com/index

National Library of Medicine. (2013). Polyvinyl Chloride (PVC). Retrieved from: http://toxtown.nlm.nih.gov/text_version/chemicals.php?id=84

Nikolić, I., \& Borović, S. (2009). Visekriterijumska optimizacija. Beograd.

Poljoprivredni institut Republike Srpske Zavod za agrohemiju i agroekologiju Banja Luka. (2009). Osnova zastite korisćenja i uredjenja poljoprivrednog zemljista Republike Srpske kao komponente procesa planiranja i korisćenja zemljista. Retrieved from: http://www.vladars.net/srSP-Cyrl/Vlada/Ministarstva/mps/Documents/Osnova\%20RS.pdf

Promethee Gaia. Retrieved from http://www.promethee-gaia.net/software.html 
Republika Srbija. (2013). Republicki zavod za statistiku. Retrieved from http://www.stat.gov.rs

Seeber, K. (1997). State-of-the-Art of Precast/ Prestressed Sandwich Wall Panels. PCI Committee Report, 42(2), 33.

Trimo. (2010). Izolovani fasadni materijal-tehnicki podaci. Retrieved from: http://www.trimo.hr/proizvodi/fasade-i-zidovi/izolirani-fasadni-sustavi-trimoterm/tehnicki-podaci/

Trmcic, S. (2008): Koncept standard SRPS ISO 14001 i zahtevi sistema menadzmenta zastitom zivotne sredine. Tematski zbornik sa medjunarodnim ucescem Tara, pp. 299-304. ISBN 978-86-8234310-3

Trmcic, S., \& Trmcic M. (2012): Application of sustainable development concept. International scientific meeting: Economics of Agriculture, Belgrade. pp.34-51 ISSN 0352-3462, UDK338.43:63

United States Environmental Protection Agency. (2014). A Citizen's Guide to Radon. Retrieved from http://www.epa.gov/radon/pubs/citguide.html

Received for publication: $\quad 30.03 .2014$

Revision received: $\quad 30.08 .2015$

Accepted for publication: $\quad 26.12 .2015$

\section{How to cite this article?}

Style - APA Sixth Edition:

Milinkovic, O., \& Trmcic, S. (2016, January 15). Ecological criteria in the function of construction methods and application of different materials. (Z. Cekerevac, Ed.) MEST Journal, 4(1), 87-98. doi:10.12709/mest.04.04.01.09

Style - Chicago Sixteenth Edition:

Milinkovic, Ozrislava, and Snezana Trmcic. 2016. "Ecological criteria in the function of construction methods and application of different materials." Edited by Zoran Cekerevac. MEST Journal (MESTE) 4 (1): 87-98. doi:10.12709/mest.04.04.01.09.

Style - GOST Name Sort:

Milinkovic Ozrislava and Trmcic Snezana Ecological criteria in the function of construction methods and application of different materials [Journal] // MEST Journal / ed. Cekerevac Zoran. - BelgradeToronto : MESTE, January 15, 2016. - 1 : Vol. 4. - pp. 87-98.

Style - Harvard Anglia:

Milinkovic, O. \& Trmcic, S., 2016. Ecological criteria in the function of construction methods and application of different materials. MEST Journal, 15 January, 4(1), pp. 87-98.

Style - ISO 690 Numerical Reference:

Ecological criteria in the function of construction methods and application of different materials. Milinkovic, Ozrislava and Trmcic, Snezana. [ed.] Zoran Cekerevac. 1, Belgrade-Toronto : MESTE, January 15, 2016, MEST Journal, Vol. 4, pp. 87-98. 